Pesq. Vet. Bras. 37(10):1101-1107, outubro 2017 DOI: $10.1590 / \mathrm{S} 0100-736 \mathrm{X} 2017001000010$

\title{
Hibridização in situ fluorescente para diagnóstico de Brachyspira hyodysenteriae e $B$. pilosicoli em suínos ${ }^{1}$
}

\author{
Saira M.N. Neves², Michelle de P. Gabardo² e Roberto M.C. Guedes ${ }^{2 *}$
}

\begin{abstract}
Neves S.M.N., Gabardo M.P. \& Guedes R.M.C. 2017. [Fluorescence in situ hybridization for diagnosis of Brachyspira hyodysenteriae e B. pilosicoli in swine.] Hibridização in situ fluorescente para diagnóstico de Brachyspira hyodysenteriae e B. pilosicoli em suínos. Pesquisa Veterinária Brasileira 37(10):1101-1107. Departamento de Clínica e Cirurgia, Escola de Veterinária, Universidade Federal de Minas Gerais, Av. Antônio Carlos 6627, Pampulha, Belo Horizonte, MG 31270-901, Brazil. E-mail: guedesufmg@gmail.com

Growing and finishing pigs are affected by pathogenic spirochetes of the genus Brachyspira sp., which cause a significant economic impact due to direct and indirect losses. Thus, efficient diagnosis of these species enables better technical intervention to prevent or treat diseases. This study aimed to evaluate the fluorescent in situ hybridization (FISH) for the diagnosis of $B$. hyodysenteriae and B. pilosicoli in histopathologic fragments of pig's intestine and compare it to the duplex PCR. Thirty-four samples collected from pigs positive for these species in at least one of the tests were used in the study. Out of the 34 analyzed intestine samples, $28(82.35 \%)$ were positive by PCR and FISH. Among the 29 B. hyodysenteriae positive samples, $23(79.3 \%)$ were positive by PCR and $21(72.4 \%)$ by FISH. There was no statistical difference among the detection rate of the used tests. Based on the fact this technique can be performed in formalin fixed tissue samples, it is practical, fast and allows the association of labeling a specific agent with histological lesions, FISH has become an alternative diagnostic method for Brachyspira hyodysenteriae and B. pilosicoli.
\end{abstract}

INDEX TERMS: Fluorescence, hybridization, diagnosis, Brachyspira hyodysenteriae, Brachyspira pilosicoli, swine, pathogenic spirochaetes, in situ molecular diagnostic, swine dysentery, spirochaetal diarrhea.

RESUMO.- Disenteria Suína e Colite Espiroquetal são duas enfermidades importantes em suínos causados pela Brachyspira hyodysenteriae e Brachyspira pilosicoli, respectivamente. 0 diagnóstico eficaz dessas espécies é extremamente importante para a adoção de estratégias adequadas para o controle. Propõe-se avaliar a técnica de hibridização in situ de fluorescência (FISH) para detecção de B. hyodysenteriae e $B$. pilosicoli em fragmentos histopatológicos de intestino de suínos e compará-la ao PCR duplex. Foram analisadas amostras de fezes e intestinos de suínos de terminação com histórico de diarreia pelas técnicas de reação em cadeia da polimerase duplex (dPCR), hibridização in situ fluorescente (FISH) para diagnóstico dessas bactérias. Foram utilizadas 34 amostras de intestino de suínos

\footnotetext{
${ }^{1}$ Recebido em 31 de julho de 2016.

Aceito para publicação em 20 de março de 2017.

${ }^{2}$ Departamento de Clínica e Cirurgia, Escola de Veterinária, Universidade Federal de Minas Gerais, Av. Antônio Carlos 6627, Pampulha, Belo Horizonte, MG 31270-901, Brasil. *Autor para correspondência: guedesufmg@ gmail.com
}

de campo positivos para alguma das duas espécies de Brachyspira sp. nos testes de FISH ou PCR. Das 34 amostras analisadas, foram detectadas $28(82,35 \%)$ positivas na PCR e no FISH. Dentre as 29 amostras positivas para B. hyodysenteriae, $23(79,3 \%)$ foram positivas à PCR e $21(72,4 \%)$ no FISH. Os resultados de FISH e PCR não diferiram estatisticamente entre si. Baseado no fato dessa técnica poder ser realizada em tecidos formolizados, ser prática, rápida e associar a marcação especifica do agente com lesões histológicas, o FISH demonstrou ser mais uma alternativa no diagnóstico de Brachyspira hyodysenteriae e B. pilosicoli.

TERMO DE INDEXAÇÃO: Hibridização, in situ fluorescência, diagnóstico, Brachyspira hyodysenteriae e Brachyspira pilosicoli, suínos, espiroquetas patogênicas, diagnóstico molecular in situ, disenteria suína, colite espiroquetal.

\section{INTRODUÇÃO}

Suínos em fase de crescimento e terminação podem ser afetados por afecções entéricas caracterizadas, principalmente, pelas diarreias (Guedes 2010). Dentre os agentes 
etiológicos causadores de diarreias nas fases finais de criação de suínos estão as bactérias do gênero Brachyspira sp. Esse gênero possui sabidamente três espécies patogênicas; Brachyspira hyodysenteriae, B. pilosicoli e B. hampsonii (Hampson \& Trott 2006, Harris et al. 2006, Burrough et al. 2012). Outras espécies não patogênicas de Brachyspira ( $B$. innocens e B. murdochii) são habitantes normais do intestino grosso de suínos, o que pode dificultar o diagnóstico. 0 quadro clinico de diarreia muco hemorrágica, altas taxas de mortalidade, e lesões graves de enterite muco hemorrágica associada a áreas de necrose são indistinguíveis entre casos de infecção por B. hyodysenteriae e B. hampsonii (Burrough et al. 2012, Rubin et al. 2013, Wilberts et al. 2014), mas $B$. hampsonii nunca foi diagnosticada no Brasil. Já a infecção por B. pilosicoli causa diarreia pastosa acinzentada com comprometimento do ganho de peso de animais recentemente alojados na fase de recria. Não cursa com mortalidade, mas o quadro clínico inicial, e as lesões macro e microscópicas são indistinguíveis das infecções causadas por B. hyodysenteriae (Hampson 2012, Guedes \& Barcellos 2012). Esse fato torna o diagnóstico definitivo difícil e dependente de exames laboratoriais complementares.

0 isolamento bacteriano em meio sólido é considerado o padrão ouro para o diagnóstico de espiroquetas patogênicas em suínos (Kennedy et al. 1988, Fellström et al. 2001). No entanto, por serem essas bactérias anaeróbias restritas, é necessário microambiente adequado; sendo o crescimento fastidioso, requerendo até seis dias ou mais para detecção de culturas específicas (Fellström et al. 2001). Assim sendo, o sucesso do isolamento está diretamente relacionado à brevidade da chegada de amostras no laboratório. Além disso, refrigeração é o método adequado de submissão de amostras clínicas para isolamento de espiroquetas, entretanto, o Brasil com dimensões continentais gera um retardo da chegada das amostras ao laboratório. Além desse material chegar impróprio para o isolamento, na maioria das vezes chega impróprio também para a avaliação microscópica das lesões, devido ao processo de autólise, quando tecido em formol não é encaminhado com as amostras frescas. Aumentar a sensibilidade de detecção de patógenos requer o desenvolvimento de técnicas que atendam aos requisitos praticidade, agilidade, sensibilidade e especificidade, considerando a possibilidade de infecções mistas (La et al. 2009, Guedes 2010). 0 Brasil vem enfrentando um número crescente de surtos de Disenteria Suína desde 2010, particularmente no estado de Santa Catarina, a partir de setembro de 2012 (Daniel et al. 2013). Em adição, ainda hoje no Brasil não houve o diagnóstico de disenteria causada pela B. hampsonii (Roberto Guedes, comunicação pessoal). Desta forma, há necessidade de aumentar a capacidade diagnóstica para a Disenteria Suína e de realização de teste que seja eficaz em garantir a diferenciação entre espécies patogênicas de Brachyspiras.

A coloração pela prata e a imuno-histoquímica são duas técnicas onde é possível a detecção de espiroquetas e caracterizá-las como pertencente ao gênero Brachyspira, entretanto não são técnicas espécie específica, não permitindo a definição da espécie de Brachyspira envolvida na lesão.
A Hibridização Fluorescente in situ (FISH) é uma técnica molecular realizada em cortes histológicos, que combina a precisão da genética molecular com a informação visual gerada com visualização do tecido ao microscópio ótico (Moter \& Gobel 2000, Ploeg 2000, Amann \& Fuchs 2008, Neves $\&$ Guedes 2012). Portanto, o FISH é uma técnica promissora a ser implantada na rotina de laboratórios de diagnóstico de enfermidades suínas, particularmente para agentes bacterianos de difícil isolamento. No Brasil, até onde se pôde constatar pela literatura, esta técnica não vem sendo utilizada para o diagnóstico de enfermidades infecciosas em animais domésticos.

Com o exposto, propõe-se utilizar a técnica de FISH para detecção de Brachyspira hyodysenteriae e B. pilosicoli em fragmentos histopatológicos de intestino grosso de suínos e compará-la ao PCR duplex para o diagnóstico destas espiroquetas.

\section{MATERIAL E MÉTODOS}

Amostras. Foram utilizadas amostras de cólon e fezes de suínos em fase de recria e terminação. Os animais eram provenientes de rebanhos com histórico de diarreia e com suspeita de infecção por Brachyspira sp. patogênicas. Das amostras obtidas, 33 foram coletas em frigoríficos, e seis foram casos enviados ao Laboratório da Patologia Veterinária da UFMG para diagnóstico. Todas as amostras utilizadas nesse estudo foram obtidas no período de março a novembro de 2011. As amostras foram acondicionadas sob refrigeração e fragmentos do cólon espiral foram fixados em formol tamponado $10 \%$, por no mínimo 24 horas. 0 intervalo médio entre a coleta e o início das análises foi de 12 horas, sendo no máximo de 48 horas. Todas as amostras de fezes e intestino grosso fixado em formol de cada animal foram submetidas à avaliação pela PCR e FISH, respectivamente. Qualquer amostra que tivesse resultado positivo em pelo menos um dos testes para $B$. pilosicoli ou $B$. hyodysenteriae foi incluída nesse estudo. Amostras positivas para ambas as espécies de Brachyspira foram consideradas amostras independentes, pois as sensibilidades dos testes variam entre as espécies bacterianas estudadas. Foram realizadas também as análises histológica e imuno-histoquímica de todos os casos, porém o resultado deste teste não foi critério para inclusão no estudo, já que não permitem o diagnóstico da espécie de Brachyspira.

Os fragmentos de intestino grosso foram processados pela técnica histológica rotineira de desidratação e inclusão em parafina. Após esse procedimento, dois fragmentos do intestino grosso foram seccionados em $3 \mu \mathrm{m}$ de espessura, e um terceiro em $6 \mu \mathrm{m}$ e corados pelas técnicas de Hematoxilina e Eosina (Luna 1968), imuno-histoquímica (Viott et al. 2013a) e FISH (Jensen et al. 2000), respectivamente.

Hibridização fluorescente in situ. 0 procedimento de FISH foi executado de acordo com Jensen et al. (2000), utilizando individualmente as sondas já descritas por Boye et al. (1998). Para a detecção d $B$. pilosicoli foi utilizada uma sonda com alvo do segmento 16S do rRNA (Pilosi209 - GCTCATCGTGAAGCGAAA) e para a B. hyodysenteriae o alvo do segmento 23sRNA (Hyo1210 - CTCACGATGAACCTTCGAC). Brevemente, os cortes de tecidos foram hidratados de acordo com a técnica histológica rotineira. A hibridização foi realizada em câmaras de hibridização ${ }^{1}$ com as lâminas montadas adequadamente em aparato próprio $^{2}$, e incubadas com $100 \mu \mathrm{l}$ de tampão de hibridização (100mM Tris, pH 7,2, 0,9 $\mathrm{M} \mathrm{NaCl}, 0,1 \%$ de dodecil sulfato de sódio) e $100 \mathrm{ng}$ de sonda, a $45^{\circ} \mathrm{C}$ por 16 horas. Após esse período, as preparações foram lavadas três vezes com tampão de hibridização pré-aquecido $\left(45^{\circ} \mathrm{C}\right)$ 
e, posteriormente, mais três vezes com a solução de lavagem pré-aquecida $\left(45^{\circ} \mathrm{C}\right)(100 \mathrm{mM}$ Tris, $\mathrm{pH} 7,2,0,9 \mathrm{M} \mathrm{NaCl})$. As amostras foram finalmente lavadas em água ultrapura durante dois minutos e secas em estufa a $45^{\circ} \mathrm{C}$. Todo o procedimento foi realizado sem a incidência de luz direta.

As preparações foram examinadas em microscópio de fluorescência (Olympus, AX70, Japão) com cubo de filtro para o fluorocromo Cy3, utilizando objetiva de imersão com aumento de 40x e óleo de imersão para fluorescência ${ }^{3}$. A marcação foi considerada positiva quando houve a visualização destacada de sinal fluorescente do agente no tecido, e negativa quando esta marcação não era observada. Como controles positivos para a técnica de FISH, foram utilizados blocos de parafina contendo fragmentos de intestino grosso sabidamente positivos para as duas espécies de Brachyspira sp. patogênicas do suíno, gentilmente cedidos pelo professor Dr. Tim Jensen do Danish Veterinary Institute, Technical University of Denmark, Dinamarca.

Imuno-histoquímica. Foi utilizada a técnica de imuno-histoquímica de acordo com o protocolo de VIOTT (2013a). Foi usada a técnica da biotina-streptavidina marcada e anticorpo policlonal específico para o gênero Brachyspira sp., gentilmente cedido pelo professor Dr. David Barcellos da UFRGS, Porto Alegre, Brasil, na diluição de 1:6000. A marcação positiva foi detectada pelo cromógeno AEC (3-Amino-9-ethylcarbazole). Como controle positivo foram utilizados cortes de os mesmos blocos de parafina cedidos pelo professor Dr. Tim Jensen, citado acima.

PCR duplex. Foi utilizada a técnica de amplificação dupla (dPCR) para B. hyodysenteriae e B. pilosicoli de acordo com o protocolo de La et al. (2006), adaptada por Viott (2013b). Os pares de primers utilizados na PCR foram respectivamente: H1 (FWH) (5'- ACTAAAGATCCTGATGTATTTG-3') e H2 (REV) (5'- CTAATAAACGTCTGCTGC-3') que tem como alvo a amplificação de um fragmento de $354 \mathrm{pb}$ no gene nox da B. hyodysenteriae; P1 (FWH) (5'- AGAGGAAAGTTTTTTCGCTTC-3') e P2 (REV) (5'- GCACCTATGTTAAACGTCCTTG-3') amplificando uma região de 823 pb do segmento $16 \mathrm{~S}$ do rRNA da B. pilosicoli.

O DNA foi extraído de todas as amostras de fezes utilizando-se o PSP Stool DNA kit, ${ }^{4}$ de acordo com instruções do fabricante. Os produtos da dPCR (amplicons) foram submetidos à eletroforese em gel de agarose a 1\% com tampão TAE $1 \mathrm{X}$, e marcados com brometo de etídio e revelados sob luz ultravioleta.

Análise estatística. As amostras incluídas no estudo foram subdivididas para análise estatística em dois grupos: amostras de $B$. hyodysenteriae e amostras de Brachyspira pilosicoli. Essa subdivisão se justifica pela diferença de sensibilidade de detecção entre cada espécie bacteriana encontrada nos testes utilizados (Boye et al. 1998, Råsbäck et al. 2006). Devido ao número amostral pequeno para B. pilosicoli, não foram realizados testes estatísticos com essas amostras.

As amostras de fezes coletadas para a PCR e amostras de tecido para o FISH foram correlacionadas, ou seja, do mesmo animal, diferindo apenas o teste utilizado; com isso os resultados do PCR e FISH foram sumarizados em tabelas $2 \times 2$ e comparados utilizando-se o método não-paramétrico de McNemar para a frequência de detecção. A concordância entre os testes foi calculada por meio do método Kappa, considerando $\mathrm{p}<0,05$, utilizando o software BioStat 5, $0^{6}$.

\section{RESULTADOS}

\section{Macroscopia e histopatologia}

Obteve-se o total de 34 amostras de intestinos de suínos positivas em pelo menos um dos testes utilizados como critério de inclusão (FISH e dPCR), sendo que, dos 34 intestinos utilizados, cinco obtiveram positividade para am- bas as bactérias (Quadro 1). Todas as amostras utilizadas no presente trabalho apresentavam algum grau de lesão macroscópica sugestiva de infecção por Brachyspira sp. As lesões localizavam-se exclusivamente no intestino grosso, principalmente no cólon, mas distribuídas não uniformemente ao longo da extensão do órgão. A mucosa do intestino grosso apresentava-se coberta por variável quantidade de muco e fibrina, associado ou não a traços de sangue e a focos de necrose superficial, formando uma membrana catarral fibrinonecrótica. 0 conteúdo variava de pastoso a líquido, avermelhado e com grande quantidade de exsudato catarral (Fig.1).

Na microscopia, as principais lesões encontradas nos animais positivos para $B$. hyodysenteriae foram erosão acentuada do epitélio de revestimento da mucosa associada a necrose moderada, focos de hemorragia e hiperplasia de células caliciformes. Infiltrado inflamatório neutrofílico moderado no lúmen de criptas com acúmulo acentuado de material basofílico amorfo também foram observados (Fig.2A). Essas alterações caracterizam o diagnóstico morfológico de enterite neutrofílica necrohemorrágica difusa acentuada associada a hiperplasia de células caliciformes. Nos intestinos positivos para B. pilosicoli, as principais le-

\section{Quadro 1. Positividade das amostras nas técnicas de PCR duplex, FISH e IHQ para Brachyspira hyodysenteriae e B. pilosicoli}

\begin{tabular}{|c|c|c|c|c|c|}
\hline \multirow[b]{2}{*}{ Amostra } & \multicolumn{2}{|c|}{ B. hyodesenteriae } & \multicolumn{2}{|c|}{ B. pilosicoli } & \multirow{2}{*}{ IHQ } \\
\hline & dPCR & FISH & PCR & FISH & \\
\hline 1 & & & + & + & +++ \\
\hline 2 & & & + & - & + \\
\hline 3 & & & + & + & + \\
\hline 4 & + & - & & & - \\
\hline 5 & + & + & & & +++ \\
\hline 6 & + & + & & & + \\
\hline 7 & + & + & & & + \\
\hline 8 & - & + & & & + \\
\hline 9 & + & - & & & - \\
\hline 10 & - & + & & & + \\
\hline 11 & & & + & - & - \\
\hline 12 & + & + & & & - \\
\hline 13 & - & + & & & - \\
\hline 14 & + & + & & & + \\
\hline 15 & + & + & - & + & $++^{*}$ \\
\hline 16 & - & + & - & + & $+++*$ \\
\hline 17 & + & + & & & +++ \\
\hline 18 & - & + & & & ++ \\
\hline 19 & + & - & - & + & $++^{*}$ \\
\hline 20 & + & + & - & + & $++^{*}$ \\
\hline 21 & + & + & & & + \\
\hline 22 & + & - & & & +++ \\
\hline 23 & + & - & & & +++ \\
\hline 24 & & & + & - & + \\
\hline 25 & + & + & - & + & $++^{*}$ \\
\hline 26 & + & - & & & ++ \\
\hline 27 & + & + & & & + \\
\hline 28 & + & + & & & + \\
\hline 29 & + & - & & & + \\
\hline 30 & + & - & & & + \\
\hline 31 & + & + & & & - \\
\hline 32 & - & + & & & - \\
\hline 33 & + & + & & & + \\
\hline 34 & + & + & & & ++ \\
\hline $\begin{array}{c}\text { Porcentagem de } \\
\text { positivos (+/total) }\end{array}$ & $\begin{array}{c}79,3 \% \\
(23 / 29)\end{array}$ & $\begin{array}{c}72,4 \% \\
(21 / 29)\end{array}$ & $\begin{array}{c}50,00 \% \\
(5 / 10)\end{array}$ & $\begin{array}{c}70,00 \% \\
(7 / 10)\end{array}$ & $\begin{array}{l}79,4 \% * \\
(27 / 34)\end{array}$ \\
\hline
\end{tabular}


sões observadas foram erosão acentuada do epitélio de revestimento da mucosa associado a hiperplasia acentuada de células caliciformes, acúmulo intenso de muco no lúmen de criptas com dilatação das mesmas e presença de bactérias na superfície do epitélio, formando a lesão conhecida como "falso bordo em escova". Porém, este "falso bordo em escova" não foi evidente em todos os casos, sendo encon- tradas em apenas duas entre os dez casos avaliados de infecção por B. pilosicoli (Fig.2A).

\section{FISH, dPCR e imuno-histoquímica}

Na técnica de FISH, 21 das 29 amostras testadas para Brachyspira hyodysenteriae foram positivas (72,4\%), enquanto sete das 10 testadas para B. pilosicoli foram posi-
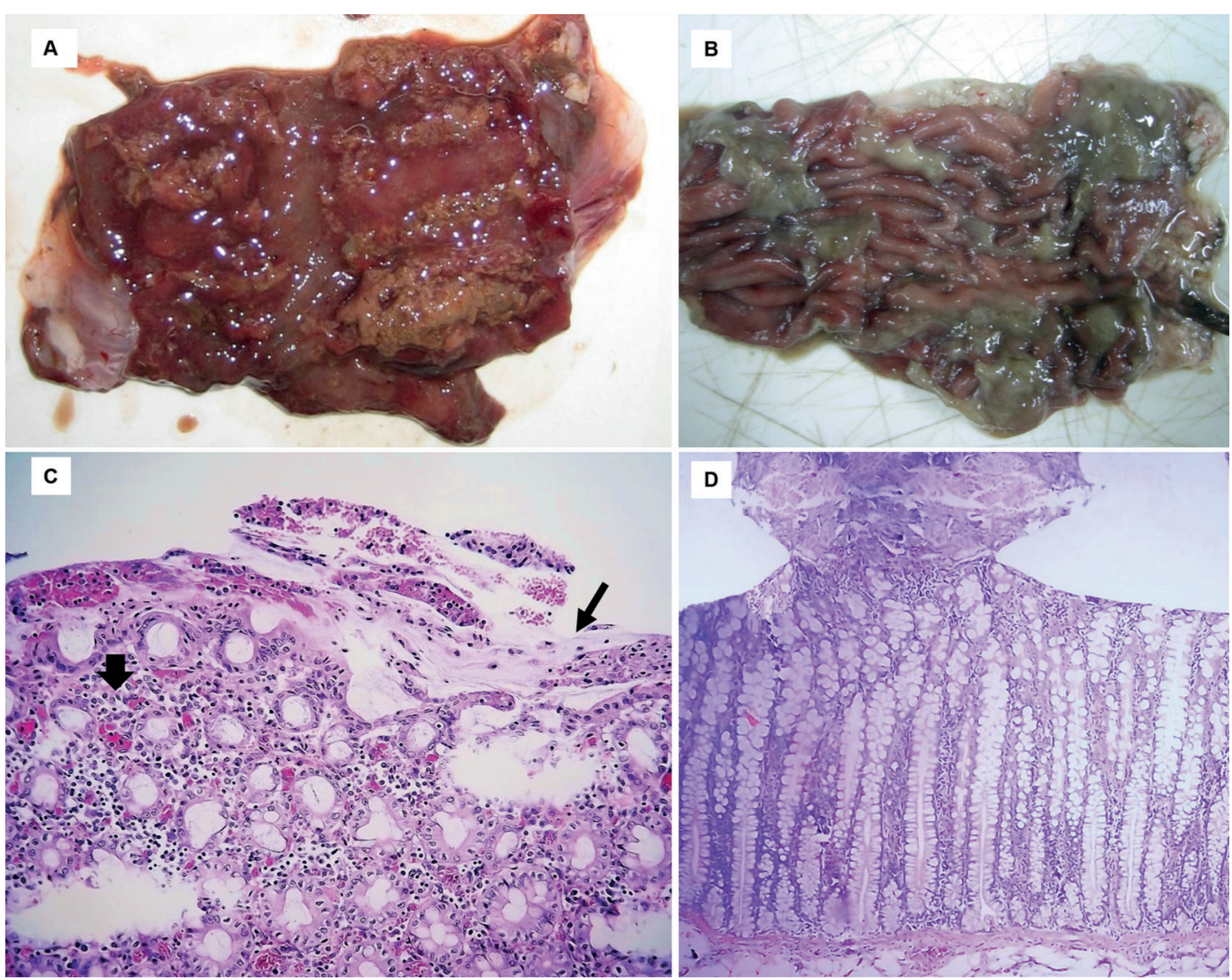

Fig.1. Característica das lesões macroscópicas e microscópicas de infecção por Brachyspira sp. observadas no presente estudo. (A) Cólon de suíno: Mucosa intestinal recoberta por muco, fibrina e associado a traços de sangue e a focos de necrose superficial, formando membrana catarral fibrinonecrótica. (B) Cólon de suíno: Mucosa intestinal recoberta por muco. As Figuras C e D representam cortes histológicos de cólon de suínos acometidos por disenteria suína e colite espiroquetal, respectivamente. (C) Necrose superficial, acúmulo de exsudato catarral (seta) e intensa congestão da mucosa (ponta de seta). HE, obj.100x. (D) Hiperplasia acentuada de células caliciformes e acúmulo de exsudato catarral no lúmen intestinal.

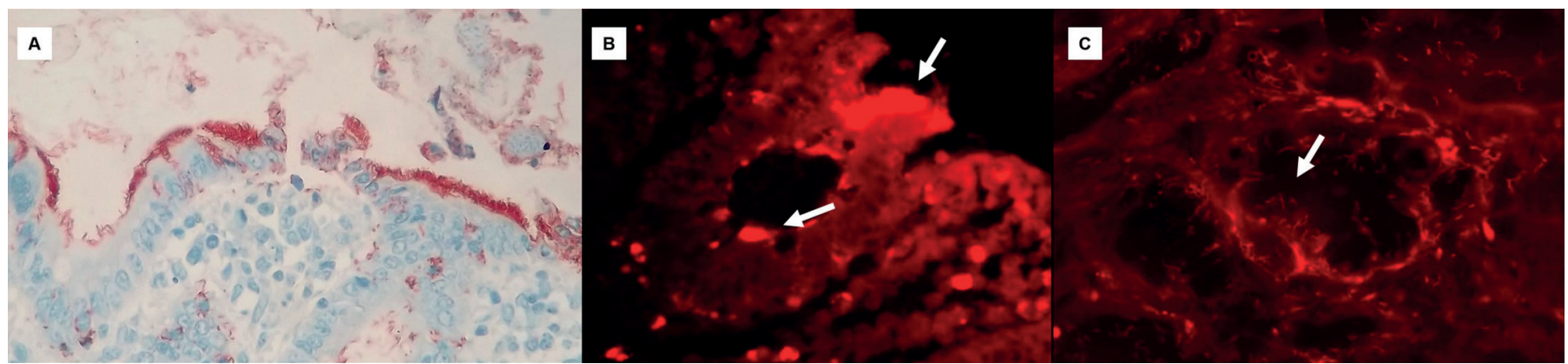

Fig.2. As figuras representam cortes histológicos de cólon de suínos acometidos por colite espiroquetal e disenteria suína. (A) Fragmento marcado por imuno-histoquímica utilizando anticorpo policlonal anti-Brachyspira sp. produzido em coelho. Nota-se a marcação em tecido de animal infectado com Brachyspira pilosicoli, com formação de "bordo em escova". Cromógeno amino-etil-carbazo - AEC, obj.20x. (B) Detecção específica de B. pilosicoli sob microscopia fluorescente, obj.4x. Filtro para fluorocromo Cy3 e a visualização de sinal forte no lúmen de cripta e na superfície epitelial (setas). (C) Detecção específica de B. hyodysenteriae, hibridizada com sonda específica marcada com Сy3. As bactérias em sinal vermelho, visualizadas individualmente na ponta das setas, são observadas entre as células da mucosa do cólon. FISH, obj.4x. 


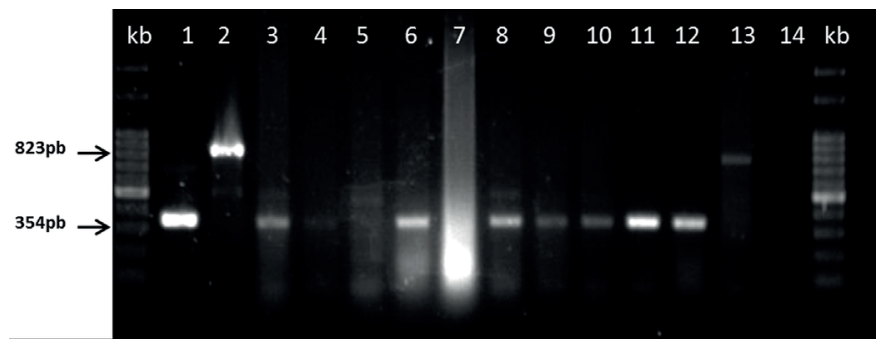

Fig.3. Análise eletroforética em gel de agarose 1\% para PCR-duplex na detecção do gene nox de Brachyspira hyodysenteriae e $16 \mathrm{~S}$ do rRNA de B. pilosicoli. Coluna $\mathrm{Kb}=$ marcador de peso molecular de $100 \mathrm{pb}$; Coluna $1=$ controle positivo de $B$. hyodysenteriae $(354 \mathrm{pb})$; Coluna $2=$ controle positivo para B. pilosicoli (823pb); Colunas 3,4,6,8,9,10,11 e 12 = Amostras positivas para $B$. hyodysenteriae; Coluna 13 = amostra positiva para B. pilosicoli; Colunas 5 e $7=$ Amostras negativas; Coluna $14=$ Controle negativo.

Quadro 2. Detecção de amostras positivas utilizando dPCR, FISH e IHQ para Brachyspira hyodysenteriae e B. pilosicoli

\begin{tabular}{lccc}
\hline Método & B. hyodysenteriae & B. pilosicoli & Total \\
\hline dPCR & $(23 / 29) 79,3 \% \mathrm{a}$ & $(5 / 10) 50 \%$ & \\
FISH & $(21 / 29) 72,4 \%^{\mathrm{a}}$ & $(7 / 10) 70 \%$ & \\
IHQ $^{*}$ & - & - & $(27 / 34) 79,41 \%{ }^{\mathrm{a}}$
\end{tabular}

Porcentagem de concordância entre os testes. Valores em coluna seguidos de letras distintas diferem entre si pelo método não-paramétrico de McNemar $(\mathrm{p}<0,05)$. * Detecção do gênero Brachyspira sp., não sendo possível a distinção entre espécies nas condições deste estudo. Devido a isso para a avaliação estatística foram considerados somente os valores totais de identificação do gênero em relação ao total de amostras avaliadas.

tivas (70\%). Importante considerar que somente cinco casos foram testados para os dois agentes pela técnica de FISH (Quadro 1). A presença dos microrganismos no tecido avaliado foi facilmente detectada devido à grande distinção entre a autofluorescência do tecido em relação ao sinal de fluorescência emitido pela sonda nas bactérias (Fig.2B e C). Utilizando a dPCR em amostras de fezes, dos 34 casos incluídos no estudo, 28 (82,35\%) foram positivas para uma das duas espiroquetas patogênicas pesquisadas (Quadro $1)$, sendo $23(58,97 \%)$ positivas para $B$. hyodysenteriae e cinco $(12,82 \%)$ B. pilosicoli.

Das 29 amostras consideradas positivas para B. hyodysenteriae em pelo menos um dos testes, a dPCR (Fig.3) detectou 79,3\% (23/29) e FISH 72,4\% (21/29) das mesmas. A frequência de detecção entre os testes não diferiu $(\mathrm{p}=0,7905)$. Quinze amostras $(51,72 \%)$ foram positivas nos dois testes, oito $(27,6 \%)$ positivas somente à $\mathrm{dPCR}$ e seis $(20,7 \%)$ somente positivo à FISH. A concordância de resultados entre dPCR e FISH foi de $51,72 \%$ no teste de Kappa ( $\mathrm{p}=0.0448)$, que é considerada uma concordância moderada segundo Landis \& Koch (1977).

Na imuno-histoquímica, que detecta somente o gênero Brachyspira, sem distinção de espécies, $79,4 \%$ dos casos $(27 / 34)$ tiveram marcação positiva, embora não tenha havido diferença estatística na frequência de detecção em relação à FISH $(\mathrm{p}=0,3877)$ ou a PCR $(\mathrm{p}=0,4240)$ (Quadro 2). Dentre essas amostras, 79,3\% (23/29) positivas para $B$. hyodysenteriae à dPCR e/ou ao FISH apresentaram marca- ção positiva. Dentre as 10 amostras positivas para B. pilosicoli à dPCR e/ou ao FISH, a imuno-histoquímica marcou bactérias do gênero Brachyspira em 9 (90\%).

\section{DISCUSSÃO}

As lesões macroscópicas encontradas estão de acordo com outros autores (Jacobson et al. 2004, Harris et al. 2006). Na microscopia as principais lesões encontradas para o grupo da B. hyodysenteriae estão de acordo com as relatadas por Jacobson et al. (2004) e Harris et al. (2006). Porém, as lesões sugestivas de Disenteria Suína, não podem ser utilizadas como forma de diagnóstico de B. hyodysenteriae. A nova espécie identificada, chamada Brachyspira hampsonii, provoca quadro clínico e patológico indistinguíveis ao de Brachyspira hyodysenteriae (Rubin et al. 2013), dificultando o diferencial dentre as mesmas. Torna-se evidente a importância de se ter um teste diagnostico padronizado para a detecção das diferentes espécies de Brachyspira sp.

Para o grupo da B. pilosicoli, a observação "falso bordo em escova" foi previamente descrito por Trott et al. (1996) e Duhamel (2001). Porém, essa alteração não é evidente em todos os casos, tendo sido encontrada em apenas duas dentre as dez avaliadas. Essa ausência de lesão pode ser atribuída à intensa erosão epitelial que ocorre em casos mais avançados ou a avaliação de poucos segmentos intestinais, não permitindo, portanto, a visualização do falso bordo em escova. Esses fatores demonstram que o diagnóstico histopatológico apenas, não é suficiente para diagnosticar nenhuma das Brachyspira sp. sendo passível a confusão com outras formas de colite.

Embora a técnica de PCR tenha apresentado bons índices de detecção, ainda houve amostras que foram negativas. Segundo Boye et al. (2001), esses resultados negativos podem ser atribuídos ao dano ou quantidade insuficiente de DNA na amostra fecal. Devido à alta sensibilidade dessa técnica, Ladinig et al. (2009) citam que a PCR é uma boa ferramenta em estudos epidemiológicos, pois são capazes de identificar animais com infecções subclínicas, sem a necessidade da eutanásia de animais, diferindo do FISH e da imuno-histoquímica que necessitam de fragmentos de tecidos para a realização da técnica. Porém, a utilização de sondas em bactérias intactas pelo FISH permite o reconhecimento histológico e a informação morfológica do microrganismo de forma específica. Além disso, devido à utilização de alvos como o rRNA, as sondas somente irão permanecer aneladas em bactérias que estavam vivas no momento da fixação (Amann \& Fuchs 2008), o que demonstra ser uma grande vantagem da FISH sobre a PCR (Boye et al. 1998).

A localização das marcações no FISH observadas no presente trabalho está de acordo com as verificadas por outros autores tanto nas infecções por $B$. hyodysenteriae como para B. pilosicoli (Jensen et al. 1998). As duas espécies apresentaram-se na maioria das vezes numerosas com orientação aleatória na camada de muco ou em estreito contato com o epitélio. Também apresentaram-se em contato com células epiteliais necróticas ou em degeneração, invadindo o espaço intercelular e membrana basal. Pode-se observar também as bactérias no lúmen de criptas e no interior de células caliciformes (Jensen et al. 1998; Jensen et 
al. 2000). Trabalhos anteriores demonstraram ser as sondas utilizadas no presente trabalho (Pilosi209 e Hyo1210) específicas para os agentes estudados. As sondas foram testadas anteriormente em tecidos e isolados de outras espécies do gênero Brachyspira, como B. innocens, B. intermedia, B. murdochii (Boye et al. 1998) e B. hampsonii (Burrough et al. 2013, Wilberts et al. 2015), não demonstrando reação cruzada entre essas espécies. Esses dados demonstram que a utilização do FISH pode ser uma ferramenta útil para a detecção de B. hyodysenteriae e B. pilosicoli no Brasil.

Apesar da alta sensibilidade observada nesse estudo da imuno-histoquímica para o gênero Brachyspira, os anticorpos não estão disponíveis comercialmente, além de não ser possível a diferenciação necessária entre as duas espécies patogênicas (B. hyodysenteriae e B. pilosicoli). Importante lembrar que a finalidade final do exame complementar no caso de colites por espiroquetas em suínos é a definição do agente, já que as consequências para rebanhos positivos para uma ou outra espécie são totalmente diferentes.

A FISH aparece como uma alternativa para o diagnóstico de Brachyspira sp., já que a confecção de sondas é altamente disponível, de fácil acesso e custo razoável (Ladinig et al. 2009), além de propiciar a identificação específica da espécie de Brachyspira patogênica. A limitação de FISH é a necessidade de microscópio com filtros de epifluorescêcia, mas laboratórios que realizam exames de imunofluorescência têm condições de executar a leitura das lâminas.

\section{CONCLUSÃo}

A técnica de FISH é uma alternativa para o diagnóstico de disenteria suína e espiroquetose colônica, podendo ser executada em amostras de tecido que tenham sido submetidas ao laboratório fixadas em formalina, gerando resultados concordantes com a PCR duplex.

Agradecimentos.- Este estudo foi financiado pela Fundação de Amparo à Pesquisa do Estado de Minas Gerais (FAPEMIG) e pelo Conselho Nacional de Desenvolvimento Científico e Tecnológico (CNPq). Saira M.N. Neves e Michelle de P. Gabardo foram bolsistas da CAPES de mestrado e doutorado, respectivamente. Roberto M.C. Guedes possui bolsa de produtividade em pesquisa do CNPq.

\section{REFERÊNCIAS}

Amann R. \& Fuchs B.M. 2008. Single-cell identification by improved FISH. Nat. Rev. Microbiol. 6(1):339-348.

Boye M., Baloda S.B., Leser T.D. \& Moller K. 2001. Survival of Brachyspira hyodysenteriae and B. pilosicoli in terrestrial microscosms. Vet. Microbiol. 81(1):33-40.

Boye M", Jensen T.K., Møller K., Leser T.D. \& Jorsal S.E. 1998. Specific detection of the genus Serpulina, S. hyodysenteriae and S. pilosicoli in porcine intestines by fluorescent rRNA in situ hybridization. Mol. Cell Probes 12(5):323-330.

Burrough E.R., Strait E.L., Kinyon J.M., Bower L.P., Madson D.M., Wilberts B.L., Schwartz K.J., Frana T.S. \& Songer J.G. 2012. Comparative virulence of clinical Brachyspira spp. isolates in inoculated pigs. J. Vet. Diagn. Invest. 24(6):1025-1034.

Burrough E.R., Wilberts B.L., Bower L.P., Jergens A.E. \& Schwartz K.J. 2013. Fluorescent in situ hybridization for detection of "Brachyspira hampsonii" in porcine colonic tissues. J. Vet. Diagn. Invest. 25(3):407-12.

Daniel A.G.S., Resende T.P., Sato J.P.H. \& Guedes R.M.C. 2013. Infecção por Brachyspira sp. em suínos no Brasil. Guia Gessulli Avicult. Suinoc. Indust. 254(5):52-58.
Duhamel G.E. 2001. Comparative pathology and pathogenesis of naturally acquired and experimentally induced colonic spirochetosis. Anim. Hlth Res. Revs 2(1):3-18.

Fellström C., Zimmerman U., Aspan A. \& Gunnarsson A. 2001.The use of culture, pooled samples and PCR for identification of herds infected with Brachyspira hyodysenteriae. Anim. Hlth Res. Revs. 2(1):37-43.

Guedes R.M.C. 2010. Controle racional das diarreias de recria e terminação. Acta Scient. Vet. 38:247-253.

Guedes R.M.C. \& Barcellos D.E.S.N. 2012. Colite espiroquetal e disenteria suína, p.122-134. In: Barcellos D.E.S.N. \& Sobestiansky J. (Eds), Doenças dos Suínos. $2^{\underline{a}}$ ed. Cânone Editorial, Goiânia.

Hampson D.J. 2012. Brachyspiral colitis, p.681-698. In: Zimmerman J.J. Karriker L.A., Ramirez A., Schwartz K.J. \& Stevenson G.W. (Eds), Diseases of Swine. 10th ed. Willey-Blackwell, Ames, Iowa.

Hampson D.J. \& Trott D.J. 2006. Spirochetal Diarrhea/porcine intestinal spirochetosis, p.553-562. In: Straw B.E., Zimmerman J.J., D’Allaire S. \& Taylor D.J. (Eds), Diseases of Swine. 9th ed. Blackwell Publishing, Ames, Iowa.

Harris D.L., Hampson D.J. \& Glock R.D. 2006. Swine dysentery, p.579-600. In: Straw B.E., Zimmerman J.J., D’Allaire S. \& Taylor D.J. (Eds), Diseases of Swine. 9th ed. Blackwell Publishing, Ames, Iowa.

Jacobson M., Fellström C., Lindberg R., Wallgren P. \& Jensen-Waern M. 2004. Experimental swine dysentery: comparison between infection models. Part 4. J. Med. Microbiol. 53:273-280.

Jensen T.K., Boye M., Moller K., Leser T.D. \& Jorsal S.E. 1998. Association of Serpulina hyodysenteriae with the colonic mucosa in experimental swine dysentery studied by fluorescent in situ hybridization. APMIS 106(11):1061-1068.

Jensen T.K., Møller K., Boye M., Leser T.D. \& Jorsal S.E. 2000. Scanning Electron Microscopy and Fluorescent in situ Hybridization of Experimental Brachyspira (Serpulina) pilosicoli infection in growing pigs. Vet. Pathol. 37(1):22-32.

Kennedy M.J., Rosnick D.K., Ulrich R.G. \& Yancey Jr R.J. 1988. Association of Treponema hyodysenteriae with Porcine Intestinal Mucosa. J. Gen. Microbiol. 134(6):1565-1576.

La T., Collins A.M., Phillips N.D., Oksa A. \& Hampson D.J. 2006. Development of a multiplex-PCR for rapid detection of the enteric pathogens Lawsonia intracellularis, Brachyspira hyodysenteriae, and Brachyspira pilosicoli in porcine faeces. Lett. Appl. Microbiol. 42(3):284-288.

La T., Phillips N.D. \& Hampson D.J. 2009. Evaluation of recombinant Bhlp29.7 as an ELISA antigen for detecting pig herds with swine dysentery. Vet. Microbiol. 133(1/2):98-104.

Ladinig A., Sommerfeldstur I. \& Weissenbock H. 2009. Comparative evaluation of diagnostic methods for Lawsonia intracellularis infection in pigs, with emphasis on cases lacking characteristic lesions. J. Comp. Pathol. 140(2/3):140-148.

Landis J.R. \& Koch G.G. 1977. The measurement of observer agreement for categorical data. Biometrics 33(1):159-1574.

Luna L.G. 1968. Routine Staining Procedures: Manual of Histologic Staining Methods of the Armed Forces Institute of Pathology. McGraw-Hill Book Co., New York, p.24-58.

Moter A. \& Gobel U.B. 2000. Fluorescence in situ hybridization (FISH) for direct visualization of microorganisms. J. Microbiol. Methods 41:85-112.

Neves S.M.N. \& Guedes R.M.C. 2012. Hibridização in situ fluorescente: princípios básicos e perspectivas para o diagnóstico de doenças infecciosas em medicina veterinária. Arqs Inst. Biológico, São Paulo, 79(4): 627-632.

Ploeg M. 2000. Cytochemical nucleic acid research during the twentieth century. Eur. J. Histochem. 44:7-42.

Råsbäck T., Fellström C., Gunnarsson A. \& Aspán A. 2006. Comparison of culture and biochemical tests with PCR for detection of Brachyspira hyodysenteriae and Brachyspira pilosicoli. J. Microbiol. Methods 66(2):347353.

Rubin J.E., Costa M.O., Hill J.E., Kittrell H.E., Fernando C., Huang Y., O'Connor B. \& Harding J.C. 2013. Reproduction of mucohaemorrhagic diarrhea 
and colitis indistinguishable from swine dysentery following experimental inoculation with "Brachyspira hampsonii" strain 30446. PLoS One 8(2):e57146.

Trott D.J., Huxtable C.R. \& Hampson D.J. 1996. Experimental infection of newly weaned pigs with human and porcine strains of Serpulina pilosicoli. Infect. Immun. (64)11:4648-4654.

Viott A.M., França S.A., Vannucci F., Cruz E.C.C., Costa M.C., Gebhart C.J. \& Guedes R.M.C. 2013a. Infection of sparrows (Passer domesticus) and different mice strains with Lawsonia intracellularis. Pesq. Vet. Bras. 33(3):372-378.

Viott A.M., Lage A.P., Cruz E.C. Jr \& Guedes RM. 2013b. The prevalence of swine enteropathogens in Brazilian grower and finish herds. Braz. J. Microbiol. 44(1):145-151.

Wilberts B.L., Arruda P.H., Kinyon J.M., Madson D.M., Frana T.S. \& Burrough E.R. 2014. Comparison of lesion severity, distribution, and colonic mucin expression in pigs with acute swine dysentery following oral inoculation with "Brachyspira hampsonii" or Brachyspira hyodysenteriae. Vet. Pathol. 51(6):1096-1108.

Wilberts B.L., Warneke H.L., Bower L.P., Kinyon J.M. \& Burrough E.R. 2015. Comparison of culture, polymerase chain reaction, and fluorescent in situ hybridization for detection of Brachyspira hyodysenteriae and "Brachyspira hampsonii" in pig feces. J. Vet. Diagn. Invest. 27(1):41-46. 